\title{
Viabilidade econômica da inclusão de óleo de girassol em dieta à base de cana-de-açúcar para vacas em lactação
}

\author{
[Economic viability of feeding different levels of sunflower oil in sugarcane-based \\ diets to lactating cows] \\ M.A. Lopes ${ }^{1,5}$, L.A. Lage $^{2}$, F.C.F. Lopes $^{3}$, M.A.S. Gama ${ }^{3}$, S.M. Souza $a^{4,5}$ \\ ${ }^{1}$ Universidade Federal de Lavras - UFLA - Lavras, MG \\ ${ }^{2}$ Aluna de pós-graduação - Universidade Federal de Lavras - UFLA - Lavras, MG \\ ${ }^{3}$ Embrapa Gado de Leite - Juiz de Fora, MG \\ ${ }^{4}$ Rowett Institute - University of Aberdeen - Escócia, Reino Unido \\ ${ }^{5}$ Bolsista do $\mathrm{CNPq}$
}

\begin{abstract}
RESUMO
Objetivou-se avaliar a viabilidade econômica da produção de leite de vacas Holandês x Gir, pela inclusão de níveis crescentes de óleo de girassol $(0,0 ; 1,5 ; 3,0$ e 4,5\%) na matéria seca de dietas baseadas em cana-deaçúcar. Os dados utilizados no estudo foram obtidos de experimento realizado com 12 vacas Holandês x Gir, multíparas, com produção média de $18,2 \mathrm{~kg} /$ dia de leite, distribuídas em três quadrados latinos 4 x 4, conforme a produção de leite, a ordem de lactação e o peso corpóreo. As dietas foram isoproteicas, fornecidas ad libitum na forma de mistura total (relação volumoso:concentrado de 60:40, base matéria seca), e os consumos das vacas determinados diariamente. As produções individuais diárias de leite foram registradas, e sua composição foi analisada quanto aos teores de gordura, proteína e ácidos graxos. A viabilidade econômica foi realizada considerando-se os preços dos ingredientes fornecidos e o consumo diário da dieta de cada tratamento. O benefício econômico foi obtido pela diferença entre a receita, com a venda do leite, e o custo com alimentação dos animais. O pagamento por qualidade foi estimado pela média de oito sistemas utilizados por empresas do ramo de laticínios, com base nos teores de gordura, proteína e no volume de leite. A dieta sem inclusão de OG foi a que proporcionou maior benefício econômico. A inclusão de OG nas dietas baseadas em cana-de-açúcar não foi viável, economicamente, devido aos gastos adicionais com OG e às penalizações resultantes da redução dos teores de proteína e de gordura do leite.
\end{abstract}

Palavras-chave: bovinocultura leiteira, economia, nutrição, qualidade do leite

\begin{abstract}
The aim of this study was to evaluate the economic viability of the milk yield of Holstein $x$ Gir cows by the addition of growing levels of sunflower oil (SO) (0.0, 1.5, 3.0 and 4.5\%) in the dry matter of sugar-cane based diets. The data utilized in the study were obtained from an experiment conducted with 12 multiparous Holstein $x$ Gir cows, with average yield of 18.2kg/day of milk, distributed into three $4 x 4$ Latin squares according to milk yield, lactation order and body weight. The diets were isoprotein, a total mixture fed at libitum (ratio roughage concentrate of 60:40, dry matter basis) and cow consumption was determined daily. The individual milk yields were recorded daily and their composition analyzed regarding fat, protein and fatty acids content. The economic viability was carried out by considering the prices of the feedstuffs fed and the daily consumption in the diet for each treatment. The economic benefit was obtained by the difference between the receipt with the milk sale and the cost with the feeding of the animals. The pay for quality was estimated on the basis of the mean of eight systems utilized by businesses in the dairy branch on the basis of the fat and protein contents and by milk volume. The diet without the addition of SO was the one which provided the greatest economic benefit. The addition of $S O$ in the sugar-cane based diets was not economically viable due to the additional expenditures with SO and the penalizations resulting from the reduction of the milk protein and fat content.
\end{abstract}

Keywords: dairy cattle, economy, milk quality, nutrition

Recebido em 18 de fevereiro de 2013

Aceito em 16 de dezembro de 2013

E-mail: malopes@dmv.ufla.br 


\section{INTRODUÇÃO}

De acordo com as estimativas da Organização Mundial de Saúde, três quartos das mortes precoces que ocorrerão no mundo até 2020 serão causadas por doenças crônicas, como a hipertensão arterial, os transtornos cardiovasculares, a diabetes, entre outras (Toral et al., 2010).

Neste sentido, nos últimos anos, diversas pesquisas vêm sendo realizadas no intuito de alterar a composição da gordura do leite, tornando-a mais adequada e saudável para o consumo humano. Um importante aspecto que normalmente implica mudanças positivas no perfil de ácidos graxos (AG) da gordura do leite de ruminantes diz respeito à suplementação de dietas com óleos vegetais e grãos de oleaginosas ricos em $\mathrm{AG}$, principalmente, em ácido linoleico (C18:2 cis-9 cis-12). Em trabalhos realizados no Brasil (Lopes et al., 2011), esta estratégia nutricional tem se mostrado eficiente para redução das concentrações dos AG saturados de cadeia média láurico (C12:0), mirístico (C14:0) e palmítico $(\mathrm{C} 16: 0)$, considerados aterogênicos e hipercolesterolêmicos. Ademais, nestas pesquisas, foi demonstrado o potencial de tais dietas em elevar as concentrações de AG considerados benéficos para a saúde humana, tais como os ácidos oleico (C18:1 cis-9), rumênico (CLA cis-9 trans-11) e vaccênico (C18:1 trans11) (Palmquist, 2010; Lopes et al., 2011).

No entanto, esta manipulação da composição dos AG do leite, que envolve a adição de lipídeos na dieta, pode resultar na depressão da síntese de gordura do leite (Lopes et al., 2011). Isto pode trazer prejuízos de ordem econômica para o produtor rural, uma vez que a gordura é componente do sistema de pagamento por composição do leite adotado no Brasil. São poucos os trabalhos que avaliaram a viabilidade econômica de dietas para vacas leiteiras, e mais escassos ainda são aqueles com foco específico na inclusão dietética de óleos vegetais, cujo preço de mercado é, de modo geral, maior que o daqueles ingredientes normalmente incluídos em dietas de ruminantes (Lopes et al., 2012). Assim, estudos de viabilidade econômica da inclusão destes e de outros ingredientes em dietas de vacas leiteiras podem subsidiar cooperativas ou laticínios na prospecção de novos nichos de mercado com apelo de marketing para alimentos mais saudáveis para nutrição humana, bem como na implementação de políticas de bonificação de pagamento ao produtor rural que produza leite naturalmente enriquecido com tais substâncias nutracêuticas.

Diante disso, objetivou-se avaliar a viabilidade econômica da produção de leite de vacas Holandês x Gir pela inclusão de óleo de girassol em dietas baseadas em cana-de- açúcar.

\section{MATERIAL E MÉTODOS}

A análise de viabilidade econômica do presente trabalho objetivou complementar os resultados obtidos por Souza (2011) em experimento realizado de agosto a setembro de 2009, no Campo Experimental José Henrique Bruschi (Coronel Pacheco, MG), de propriedade da Embrapa Gado de Leite, que avaliou o efeito da inclusão de $0 ; 1,5 ; 3,0$ e 4,5\% de óleo de girassol (OG) na matéria seca (MS) da dieta sobre o consumo, a produção, a composição e o perfil de AG do leite de vacas alimentadas com cana-de-açúcar (Saccharum officinarum) cultivar RB 739735, fornecida picada, suplementada com concentrado. Todos os procedimentos experimentais utilizados seguiram os princípios de ética e bem-estar animal preconizados na Embrapa Gado de Leite.

Foram utilizadas 12 vacas Holandês x Gir, multíparas, com 96 dias de lactação, distribuídas em três quadrados latinos 4 x 4, contemporâneos e balanceados para efeito residual, e organizados de acordo com a produção de leite, a ordem de lactação e o peso corpóreo das vacas. Na Tab. 1, têm-se a proporção dos ingredientes e a composição química das dietas, que foram formuladas para serem isoproteicas e atender às exigências nutricionais de uma vaca com $500 \mathrm{~kg}$ de peso corporal, produzindo, diariamente, $17 \mathrm{~kg}$ de leite e com ganho de peso de $0,30 \mathrm{~kg} / \mathrm{dia}$, segundo o NRC (National..., 2001).

As vacas foram alojadas em baias coletivas do tipo free stall, e o consumo individual de MS foi determinado diariamente utilizando-se cochos com portões eletrônicos do tipo calan-gate (American Calan Inc., Northewood, EUA), sendo as dietas fornecidas ad libitum, como mistura total, uma vez ao dia, após a ordenha da manhã. 
Foi realizado o registro das produções individuais de leite nas duas ordenhas diárias (seis e 14h), e, após a homogeneização do leite ordenhado de cada vaca, foram coletadas, em frascos contendo bronopol como conservante, amostras representativas das produções individuais diárias de leite. As amostras foram encaminhadas ao Laboratório de Qualidade do Leite da Embrapa Gado de Leite
(Juiz de Fora, MG), onde foram analisadas quanto aos teores de gordura e proteína. Foram também obtidas amostras individuais de leite das vacas, em frascos sem conservante, que foram armazenadas $\left(-20^{\circ} \mathrm{C}\right) \mathrm{e}$, posteriormente, processadas para análise dos AG rumênico e vaccênico, realizada no Laboratório de Cromatografia da Embrapa Gado de Leite (Juiz de Fora, MG).

Tabela 1. Ingredientes e composição química das dietas baseadas em cana-de-açúcar com diferentes níveis de inclusão de óleo de girassol, com base na matéria seca ${ }^{1}$

\begin{tabular}{lcccc}
\multirow{2}{*}{ Ingredientes } & \multicolumn{3}{c}{$\begin{array}{c}\text { Nível de inclusão de óleo de girassol } \\
\text { (\% da matéria seca da dieta) }\end{array}$} \\
\cline { 2 - 5 } & 0 & 1,5 & 3,0 & 4,5 \\
\hline Cana-de-açúcar & 60,0 & 60,0 & 60,0 & 60,0 \\
Polpa cítrica & 8,5 & 11,8 & 16,8 & 17,0 \\
Milho moído & 16,5 & 10,9 & 3,9 & 2,0 \\
Farelo de soja & 13,30 & 13,80 & 14,25 & 14,40 \\
Óleo de girassol & 0,0 & 1,5 & 3,0 & 4,5 \\
Ureia + sulfato de amônio (9:1) & 1,05 & 1,05 & 1,05 & 1,05 \\
Suplemento mineral-vitamínico comercial & 0,96 & 0,98 & 1,03 & 1,06 \\
\hline & & & & \\
\hline Composição química & & & & \\
\hline Proteína bruta & 14,48 & 14,49 & 14,47 & 14,55 \\
Extrato etéreo & 3,13 & 4,55 & 5,98 & 7,42 \\
Fibra em detergente neutro & 40,52 & 40,36 & 40,20 & 40,08 \\
Nutrientes digestíveis totais & 66,89 & 68,27 & 69,76 & 71,55 \\
\hline
\end{tabular}

${ }^{1}$ Dietas formuladas segundo o NRC (2001).

A avaliação econômica foi realizada utilizandose o sistema computacional CU\$TO DIETAS (Lage et al., 2011). Foram consideradas a receita com a venda do leite $(\mathrm{R} \$ 0,8827 / \mathrm{kg})$ e as despesas com alimentação para cada tratamento, sendo todos os valores cotados no mercado de Lavras, MG, em novembro de 2011. O benefício econômico foi calculado pela diferença entre a receita com a venda do leite e as despesas com a alimentação dos animais (Lopes et al., 2012).

Realizou-se uma simulação do pagamento do leite por qualidade praticado por oito empresas do ramo de laticínios. De acordo com o critério utilizado (Tab. 2), as bonificações foram de $\mathrm{R} \$ 0,0023$ e $\mathrm{R} \$ 0,0003 / \mathrm{kg}$ de leite para percentuais de gordura e proteína iguais a 3,35 e 3,03 , respectivamente. Os valores recebidos eram crescentes e proporcionais, conforme aumento desses componentes no leite. Teores de proteína e gordura inferiores a 2,93 e $2,89 \%$ eram penalizados em $\mathrm{R} \$-0,0050$; $\mathrm{R} \$-0,0173$, respectivamente. Nenhum dos laticínios bonificava por teores de ácidos graxos.
Tendo em vista analisar como poderia ser a situação em período de safra e de entressafra e levando-se em consideração o fato de que os preços dos insumos e do leite sofrem oscilações, realizou-se a análise de cenários MOP: mais provável - otimista - pessimista, utilizada por Gropelli e Nikbakht (2002). Tomou-se como base o cenário real, que seria o mais provável, ou seja, preços praticados no mercado por ocasião da realização da pesquisa. Simularam-se os cenários pessimista e otimista. No otimista, consideraram-se as seguintes situações: a) preço do leite normal e insumos baixos; b) preço do leite alto e insumos baixos; c) preço do leite alto e insumos normais; no pessimista: d) preço do leite normal e insumos altos; e) preço do leite baixo e insumos normais; f) preço do leite baixo e insumos altos. Consideraram-se, ainda, os cenários alternativos: g) leite e insumos altos; h) leite e insumos baixos, devido ao fato de, ao planejar a simulação, não ser possível prever se seriam otimistas ou pessimistas. Quanto aos valores de insumos altos, consideraram-se as 
altas dos preços dos ingredientes com maiores representatividades, ou seja, farelo de soja, milho e OG de 7,55; 20,60; 17,36\%, respectivamente, ocorridas na entressafra do ano anterior. Quanto aos insumos baixos, consideraram-se as reduções nos preços de 24,34; 25,46; 5,83\%, respectivamente, em relação aos preços praticados no cenário real. Em relação ao leite, os preços foram de $\mathrm{R} \$ 0,8929 ; \mathrm{R} \$ 1,01$ ( $\mathrm{R} \$ 0,8929$ $+13,53 \%)$ e $\mathrm{R} \$ 0,77(\mathrm{R} \$ 0,8929-13,53 \%) / \mathrm{kg}$ de leite nos cenários real, otimista e pessimista, respectivamente. Todos os percentuais de altas e baixas de preços foram levantados com base nas cotações nos períodos de entressafra e safra (2010-2011), respectivamente, do ano anterior.

Tabela 2. Produção e teores de gordura, de proteína e dos ácidos graxos (AG) vaccênico e rumênico no leite de vacas Holandês x Gir que receberam dietas baseadas em cana-de- açúcar, suplementadas (base MS) com diferentes níveis de inclusão de óleo de girassol (OG), e valores (R\$) recebidos por kg de leite, teores de proteína, gordura e $\mathrm{AG}^{1}$

\begin{tabular}{|c|c|c|c|c|c|c|c|c|c|c|}
\hline \multirow{2}{*}{$\begin{array}{l}\text { Inclusão de } \\
\text { OG } \\
(\% \text { na dieta) }\end{array}$} & \multicolumn{2}{|c|}{ Volume } & \multicolumn{2}{|c|}{ Proteína } & \multicolumn{2}{|c|}{ Gordura } & \multicolumn{2}{|c|}{ AG vaccênico } & \multicolumn{2}{|c|}{ AG rumênico } \\
\hline & $\mathrm{kg} / \mathrm{dia}$ & $\mathrm{R} \$ *$ & $\%$ & $\mathrm{R} \$ *$ & $\%$ & $\mathrm{R} \$ *$ & $\begin{array}{c}g / 100 g \text { de } \\
A G\end{array}$ & $\mathrm{R} \$ *$ & $\begin{array}{c}g / 100 g \text { de } \\
A G\end{array}$ & $\mathrm{R} \$ *$ \\
\hline 0,0 & 18,0 & 0,8929 & 3,03 & $+0,0003$ & 3,43 & $+0,0036$ & 1,12 & 0,0000 & 0,54 & 0,0000 \\
\hline 1,5 & 18,3 & 0,8929 & 2,79 & $-0,0169$ & 3,28 & $+0,0000$ & 3,36 & 0,0000 & 1,40 & 0,0000 \\
\hline 3,0 & 17,4 & 0,8929 & 2,93 & $-0,0050$ & 2,89 & $-0,0173$ & 6,42 & 0,0000 & 2,34 & 0,0000 \\
\hline 4,5 & 19,2 & 0,8929 & 2,90 & $-0,0085$ & 2,67 & $-0,0227$ & 7,54 & 0,0000 & 2,75 & 0,0000 \\
\hline
\end{tabular}

${ }^{1}$ Os dados de volume e composição do leite foram obtidos em Souza (2011).

*Considerando-se a média de pagamento praticado por oito laticínios, no ano de 2011; AG vaccênico (C18:1 trans11); AG rumênico (CLA cis-9 trans-11).

\section{RESULTADOS E DISCUSSÃO}

Conforme apresentado por Souza (2011), não houve efeito $(\mathrm{P}>0,05)$ da inclusão de $\mathrm{OG}$ nas dietas sobre o consumo de matéria seca, a produção de leite e o teor e a produção de proteína do leite. Por outro lado, houve efeito linear $(\mathrm{P}<0,03)$ decrescente sobre a produção e o teor de gordura do leite (Tab. 3). Os teores dos AG de cadeia média láurico, mirístico e palmítico foram linearmente reduzidos $(\mathrm{P}<0,0001)$ em razão do incremento no nível de OG nas dietas (Souza, 2011), enquanto os AG oleico, rumênico e vaccênico apresentaram aumento linear $(\mathrm{P}<0,0001)$ em suas concentrações (Tab. 3; Souza, 2011), evidenciando a produção de leite com elevado potencial nutracêutico.

A dieta sem inclusão de OG foi considerada mais atrativa economicamente por apresentar menor custo alimentar (R\$6,72/vaca/dia) e maior benefício econômico (R $\$ 9,35 / \mathrm{vaca} / \mathrm{dia})$ em relação a todas as outras (Tab. 3 ).

O milho e o farelo de soja nas dietas sem e com $1,5 \%$ de $\mathrm{OG}$ foram os mais representativos economicamente, enquanto o OG, apesar de seu baixo nível de utilização em relação aos dos outros ingredientes nas dietas, mas por seu elevado custo por $\mathrm{kg}$ de MS $(\mathrm{R} \$ 5,38)$, tornou-se mais representativo nas dietas com maiores níveis de inclusão $(3,0$ e 4,5\%), constituindo o principal responsável por elevar os custos alimentares (Tab. 4).

O menor custo alimentar/kg de leite (Tab. 5) foi do tratamento sem inclusão de OG ( $\mathrm{R} \$ 0,3733)$. Esse ingrediente foi responsável por tornar as dietas em que ele foi incluído mais onerosas. Houve variação entre os tratamentos de $\mathrm{R} \$ 0,1468$ ( $\mathrm{R} \$ 0,5201$ a $\mathrm{R} \$ 0,3733$ ) (Tab. 5), por $\mathrm{kg}$ de leite produzido; valor considerável dentro do item alimentação, que tem majorados os custos de produção, podendo apresentar variações de 52,23\% (Lopes et al., 2008) até $66,49 \%$ (Lopes et al., 2005). Essa variação de $\mathrm{R} \$ 0,1468 / \mathrm{kg}$ em um rebanho hipotético de 50 vacas, com produção média de leite de $18 \mathrm{~kg} / \mathrm{dia}$, renderia, em um mês, $\mathrm{R} \$ 3.963,60$ ( $\mathrm{R} \$ 0,1468$ x 50 vacas $\times 18 \mathrm{~kg} /$ vaca $\times 30$ dias), tornando-se muito atrativa economicamente. 
Tabela 3. Valores médios diários de consumo, produção e composição do leite, receita, custo alimentar e benefício econômico de vacas que receberam dietas baseadas em cana-de-açúcar com diferentes níveis de inclusão de óleo de girassol

\begin{tabular}{|c|c|c|c|c|c|}
\hline \multirow[b]{2}{*}{ Variável } & \multicolumn{5}{|c|}{$\begin{array}{l}\text { Nível de inclusão de óleo de girassol } \\
\text { (\% da matéria seca da dieta) }\end{array}$} \\
\hline & 0 & 1,5 & 3,0 & 4,5 & $\begin{array}{c}\text { Valor de } \mathrm{P} \\
\text { para efeito } \\
\text { linear }\end{array}$ \\
\hline A- Consumo de matéria seca $(\mathrm{kg} / \mathrm{vaca} / \mathrm{dia})^{1}$ & 15,7 & 15,9 & 16,1 & 14,8 & $\mathrm{~ns}^{5}$ \\
\hline B- Produção de leite $(\mathrm{kg} / \mathrm{vaca} / \mathrm{dia})^{1}$ & 18,0 & 18,3 & 17,4 & 19,2 & ns \\
\hline C- Produção de proteína (g/vaca/dia) ${ }^{1}$ & 543 & 511 & 510 & 555 & ns \\
\hline D- Teor de proteína $(\%)^{1}$ & 3,03 & 2,79 & 2,93 & 2,90 & ns \\
\hline E- Produção de gordura (g/vaca/dia) ${ }^{1}$ & 618 & 608 & 501 & 512 & 0,023 \\
\hline F- Teor de gordura $(\%)^{1}$ & 3,43 & 3,28 & 2,89 & 2,67 & 0,001 \\
\hline G- Teor de ácido vaccênico ( $\mathrm{g} / 100 \mathrm{~g}$ de ácidos graxos totais $)^{1}$ & 1,12 & 3,36 & 6,42 & 7,54 & $<0,0001$ \\
\hline $\mathrm{H}-$ Teor de ácido rumênico (g/100 g de ácidos graxos totais) ${ }^{1}$ & 0,54 & 1,40 & 2,34 & 2,75 & $<0,0001$ \\
\hline I- Receita com leite/vaca/dia $(\mathrm{R} \$)^{2}$ & 16,07 & 16,34 & 15,54 & 17,14 & \\
\hline $\mathrm{J}$ - Custo alimentar/vaca/dia $(\mathrm{R} \$)^{3}$ & 6,72 & 7,88 & 9,05 & 9,37 & \\
\hline K- Benefício econômico/vaca/dia $(\mathrm{R} \$)^{4}$ & 9,35 & 8,46 & 6,49 & 7,77 & \\
\hline
\end{tabular}

${ }^{1}$ Fonte: Souza (2011); ${ }^{2}(\mathrm{I}=\mathrm{B}$ x R $\$ 0,8929) ;{ }^{3}$ (soma do consumo de cada um dos ingredientes, com base na MS x preços $/ \mathrm{kg}$ de cada ingrediente $) ;{ }^{4}(\mathrm{~K}=\mathrm{I}-\mathrm{J}) ;{ }^{5} \mathrm{~ns}=$ não significativo $(\mathrm{P}>0,05)$.

Tabela 4. Preço dos insumos, por $\mathrm{kg}$ e em $\mathrm{R} \$ /$ vaca/dia, utilizados nas dietas, e representatividade, em \%, de cada ingrediente sobre o valor total de cada dieta/vaca/dia

\begin{tabular}{|c|c|c|c|c|c|c|c|c|c|}
\hline \multirow{3}{*}{ Ingrediente } & \multirow{3}{*}{$\begin{array}{c}\text { Preço* } \\
(/ \mathrm{kg})\end{array}$} & \multicolumn{8}{|c|}{ Nível de inclusão de óleo de girassol (\% na matéria seca da dieta) } \\
\hline & & \multicolumn{2}{|c|}{0} & \multicolumn{2}{|l|}{1,5} & \multicolumn{2}{|c|}{3,0} & \multicolumn{2}{|l|}{4,5} \\
\hline & & $\begin{array}{c}\mathrm{R} \$ \\
\text { (/vaca/dia) }\end{array}$ & $\%^{* *}$ & $\begin{array}{c}\mathrm{R} \$ \\
\text { (/vaca/dia) }\end{array}$ & $\%^{* *}$ & $\begin{array}{c}\mathrm{R} \$ \\
\text { (/vaca/dia) }\end{array}$ & $\%^{* *}$ & $\begin{array}{c}\mathrm{R} \$ \\
\text { (/vaca/dia) }\end{array}$ & $\%^{* *}$ \\
\hline Milho moído & 0,69 & 1,79 & 26,64 & 1,20 & 15,23 & 0,44 & 4,87 & 0,21 & 2,24 \\
\hline Farelo de soja & 0,95 & 1,99 & 29,61 & 2,09 & 26,52 & 2,19 & 24,23 & 2,03 & 21,66 \\
\hline Polpa cítrica & 0,58 & 0,78 & 11,61 & 1,10 & 13,96 & 1,57 & 17,37 & 1,47 & 15,69 \\
\hline Minerais/vitaminas & 1,73 & 0,26 & 3,87 & 0,27 & 3,43 & 0,29 & 3,21 & 0,27 & 2,88 \\
\hline Óleo de girassol & 5,38 & 0,00 & 0,00 & 1,29 & 16,37 & 2,58 & 28,54 & 3,60 & 38,42 \\
\hline Ureia & 1,44 & 0,24 & 3,57 & 0,24 & 3,05 & 0,24 & 2,65 & 0,22 & 2,35 \\
\hline Cana-de-açúcar & 0,18 & 1,66 & 24,70 & 1,69 & 21,45 & 1,73 & 19,14 & 1,57 & 16,76 \\
\hline TOTAL & & 6,72 & 100,0 & 7,88 & 100,0 & 9,05 & 100,0 & 9,37 & 100,0 \\
\hline
\end{tabular}

*Cotados em novembro de 2011, na região sul de Minas Gerais; **(valor do ingrediente/valor da dieta) x100.

Tabela 5. Custo alimentar, bonificação pelos teores de proteína, gordura e de ácidos graxos, receita, benefício econômico, por $\mathrm{kg}$ de leite e vaca/dia em dietas baseadas em cana-de-açúcar suplementadas com óleo de girassol (OG)

\begin{tabular}{lcccc}
\hline \multirow{2}{*}{ Item } & \multicolumn{4}{c}{ Nível de inclusão de OG (\% da matéria seca da dieta) } \\
\cline { 2 - 5 } & 0 & 1,5 & 3,0 & 4,5 \\
\hline A- Custo alimentar/kg de leite (R\$) & 0,3733 & 0,4306 & 0,5201 & 0,4880 \\
B- Pagamento e bonificação/kg de leite (R\$)* & 0,8929 & 0,8929 & 0,8929 & 0,8929 \\
C- Bonificação teor proteína/kg de leite (R\$)* & 0,0003 & $-0,0169$ & $-0,0050$ & $-0,0085$ \\
D- Bonificação teor gordura/kg de leite (R\$)* & 0,0036 & 0,0000 & $-0,0173$ & $-0,0227$ \\
E- Bonificação por ácidos graxos* & 0,0000 & 0,0000 & 0,0000 & 0,0000 \\
F- Receita (R $/ \mathrm{kg})(\mathrm{B}+\mathrm{C}+\mathrm{D}+\mathrm{E})$ & 0,8968 & 0,8760 & 0,8706 & 0,8617 \\
G- Benefício econômico (R\$/kg) (F-A) & 0,5235 & 0,4454 & 0,3505 & 0,3737 \\
H- Produção (kg/dia) & 18,0000 & 18,3000 & 17,4000 & 19,2000 \\
I- Benefício econômico/vaca/dia (R\$) (G x H) & 9,4222 & 8,1512 & 6,0979 & 7,1752 \\
\hline
\end{tabular}

*Critério utilizado com base na média dos preços pagos por oito laticínios da região sul de Minas Gerais, no ano de 2011. 
Neste estudo, realizou-se a simulação do pagamento por qualidade do leite praticado por oito laticínios da região sul de Minas Gerais. Com base no critério utilizado, apenas a dieta controle, sem inclusão de OG, seria bonificada por apresentar teor de proteína no leite de 3,03\%; as demais seriam penalizadas (Tab. 5) por apresentarem teores entre 2,79 e 2,93\%. A dieta sem inclusão de OG seria bonificada por ter obtido teor de gordura no leite igual a $3,43 \%$, enquanto a dieta com $1,5 \%$ de inclusão de $\mathrm{OG}$ estaria na faixa de neutralidade (teor em 3,28\%), e, portanto, não receberia bonificação nem penalização. Todos seriam bonificados pelo volume de leite e receberiam o mesmo valor por estarem na mesma faixa.

Os benefícios econômicos apresentaram diferença de $\mathrm{R} \$ 0,1730 / \mathrm{kg}$ de leite $(\mathrm{R} \$ 0,5235$ $\mathrm{R} \$ 0,3505)$ entre os tratamentos sem OG e com $3,0 \%$, respectivamente (Tab. 5), devido ao menor custo alimentar ( $\mathrm{R} \$ 0,3733)$, aliado às bonificações pelos teores de gordura $(\mathrm{R} \$ 0,0036)$ e proteína (R $\$ 0,0003)$. Estas duas dietas receberam as maiores bonificações para esses componentes em relação às demais. Tal fato evidencia que resultados econômicos positivos não são provenientes apenas do aumento da produção de leite, mas, principalmente neste caso, da redução do custo de produção, pelo menor custo alimentar, corroborando os resultados de pesquisas obtidos por Lopes et al. (2005), Lopes et al. (2008) e Santos e Lopes (2012), ao mostrarem que, entre os grupos de componentes do custo operacional efetivo, a alimentação é a que mais impacta o custo de produção do leite. A diferença dos benefícios $(\mathrm{R} \$ 0,1730)$ por $\mathrm{kg}$ de leite produzido renderia, em um mês, em um rebanho hipotético de 50 vacas, com produção média de $18 \mathrm{~kg} / \mathrm{vaca} / \mathrm{dia}$, $\mathrm{R} \$ 4.671,00(0,1730 \times 50 \times 18 \times 30)$.

O custo alimentar adicional com OG (Tab. 6) representa a subtração do custo alimentar/vaca/dia (Tab. 3) da dieta sem OG pelos níveis de inclusão estudados. Os valores recebidos pelas bonificações dos teores de gordura, proteína e $A G$ não foram suficientes para pagar as despesas adicionais com a inclusão de OG nas dietas e resultaram em saldos negativos nos tratamentos com 1,5; 3,0 e 4,5\%, o que evidencia a inviabilidade econômica da inclusão de $\mathrm{OG}$ nas dietas testadas. Apenas a dieta controle apresentou saldo positivo (Tab. 6). Resultados semelhantes foram obtidos por Lopes et al. (2012), ao analisarem a viabilidade econômica da inclusão de óleo de soja em dietas para vacas Holandês x Gir que receberam dietas baseadas na gramínea tropical capim-elefante (Pennisetum purpureum).

Tabela 6. Viabilidade econômica da inclusão de diferentes níveis de óleo de girassol (OG) na matéria seca (MS) das dietas baseadas em cana-de-açúcar, em razão das bonificações pelos teores de proteína, gordura e ácidos graxos no leite

\begin{tabular}{lcccc}
\hline & \multicolumn{4}{c}{ Nível de inclusão de OG (\% da MS da dieta) } \\
\cline { 2 - 5 } Item & 0 & 1,5 & 3,0 & 4,5 \\
\hline A- Custo alimentar adicional com OG/animal/dia (R\$) & 0,000 & 1,1600 & 2,3300 & 2,6500 \\
B- Bonificação pela proteína (R\$)* & 0,0054 & $-0,3093$ & $-0,0870$ & $-0,1632$ \\
C- Bonificação pela gordura (R\$)** & 0,0648 & 0,0000 & $-0,3010$ & $-0,4358$ \\
D- Bonificação por ácidos graxos (R\$)*** & 0,0000 & 0,0000 & 0,0000 & 0,0000 \\
E- Saldo = (B + C) - A (R\$) & 0,0702 & $-1,4693$ & $-2,7180$ & $-3,2490$ \\
F- Viabilidade econômica & SIM & NÃO & NÃO & NÃO \\
\hline
\end{tabular}

*Valor da bonificação pela proteína/kg de leite x produção de leite.

** Valor da bonificação pela gordura/kg de leite x produção de leite.

***valor da bonificação por ácidos graxos/kg de leite x produção de leite, segundo o critério utilizado com base nas médias dos preços pagos por oito laticínios na região sul de Minas Gerais, no ano de 2011. 
Como não há pagamento no Brasil por teor de AG no leite, não se faz viável, sob o olhar econômico, incluir OG nas dietas, a despeito das diferenças observadas nos teores de ácido vaccênico e rumênico no leite (Tab. 3). Acreditase que o mercado lácteo, futuramente, investirá esforços na busca de produtos inovadores, com visão de mercado não somente para produtos seguros, livres de contaminantes e resíduos, com comprovada qualidade composicional e higiênica, mas também para aqueles com elevado potencial nutracêutico (Lopes et al., 2012), quer pelo incremento nos teores de determinados $\mathrm{AG}$ (e.g. oleico, rumênico, vacênico) e/ou também pela redução de outros (e.g. AG de cadeia média láurico, mirístico e palmítico). Atualmente, o sinônimo de qualidade adotado no Brasil se resume a produtos oriundos da ordenha completa, ininterrupta, em condições de higiene, de vacas sadias, bem alimentadas e descansadas, para cumprimento das metas estabelecidas pela Instrução Normativa 62 (Brasil, 2011), o que difere do adotado em determinados países, que têm se preocupado cada vez mais em comercializar produtos mais saudáveis (Dónega, 2010).

A bonificação no pagamento pela produção de leite naturalmente enriquecido com AG benéficos à saúde humana (e.g. ácidos rumênico e vaccênico) poderia beneficiar toda a cadeia produtiva do leite, desde os produtores que receberiam maior remuneração; indústrias $\mathrm{e}$ hipermercados, que poderiam receber preço diferenciado pela comercialização de produtos inovadores; e consumidores, que estariam investindo em qualidade de vida. No entanto, nos dias atuais, no Brasil ainda não há leite ou derivados lácteos no mercado com tal apelo de marketing; tampouco existem, por parte da indústria laticinista, iniciativas direcionadas à implementação de políticas de bonificação de pagamento ao empreendedor rural que produza este tipo diferenciado e mais saudável de leite. Outro aspecto que aparentemente é negativo, mas que também poderia ser explorado pelo lado positivo em face das atuais recomendações dietéticas de menor consumo de gorduras associado à manutenção de hábitos mais saudáveis de vida, diz respeito ao caráter naturalmente desnatado (light) deste tipo de leite enriquecido com AG benéficos à saúde (Tab. 3).

Os resultados apresentados referem-se ao cenário real, com preços praticados à época da realização da pesquisa. Como os preços dos insumos e do leite sofrem oscilações ao longo do ano, realizouse a análise de cenários MOP: mais provável otimista - pessimista (Gropelli e Nikbakht, 2002). Em todos os cenários estudados, a dieta que apresentou melhor viabilidade econômica foi a controle (sem adição de OG). Na situação analisada, com base no cenário real, constatou-se que, quando o produtor for penalizado pelos teores de proteína e gordura, o aumento no preço do leite torna mais desvantajoso economicamente o acréscimo de OG nas dietas analisadas.

Considerando-se os resultados obtidos nesta pesquisa, não foi viável, economicamente, a inclusão de OG nas dietas de vacas leiteiras. Lopes et al. (2012) sugeriram que, semelhantemente a políticas de pagamento praticadas por muitas indústrias laticinistas, no que se refere à contagem de células somáticas e de bacteriana total e aos teores de proteína e gordura do leite, bonificações sejam, de alguma forma, pagas aos pecuaristas, incentivando-os a produzirem leite com elevado potencial nutracêutico, que beneficia a saúde dos consumidores.

\section{CONCLUSÕES}

A inclusão de óleo de girassol nas dietas de vacas Holandês x Gir baseadas em cana-deaçúcar não foi viável economicamente, devido aos gastos adicionais com esse ingrediente dietético e às penalizações resultantes da redução dos teores de proteína e gordura do leite.

\section{AGRADECIMENTOS}

Os autores agradecem à Fapemig e ao $\mathrm{CNPq}$, pelo apoio na realização deste estudo. 


\section{REFERÊNCIAS}

BRASIL, 2011. MAPA. Instrução normativa $n^{\circ}$ 62, de 29 de dezembro de 2011 - Regulamento Técnico de Produção, Identidade e Qualidade do Leite tipo A, Regulamento Técnico de Identidade e Qualidade de Leite Cru Refrigerado, o Regulamento Técnico de Identidade e Qualidade de Leite Pasteurizado e o Regulamento Técnico da Coleta de Leite Cru Refrigerado e seu Transporte a Granel. Diário Oficial da União, Brasília, 2011.

DÓNEGA, J.M. Innovácion em PYMES del sector lácteo. In: VILELA, D.; FERNANDES, E.N.; ZOCCAL, R. et al. (Ed). Estratégias e conhecimentos para o fortalecimento do agronegócio do leite, Juiz de Fora, Embrapa Gado de Leite. 2010. 280p.

GROPELLI, A.A.; NIKBAKHT, E. Administração Financeira. 2.ed. São Paulo: Saraiva, 2002. $512 \mathrm{p}$.

LAGE, L.A.; LOPES, M.A.; REIS, M.P. et al. Desenvolvimento de um sistema computacional para avaliação do custo:benefício de diferentes dietas na atividade leiteira. In: REUNIÃO ANUAL DA SOCIEDADE BRASILEIRA DE ZOOTECNIA, 48., 2011, Belém. Anais... Belém: SBZ, 2011.

LOPES, M.A.; DIAS, A.S.; CARVALHO, F.M. et al. Resultados econômicos de sistemas de produção de leite com diferentes níveis tecnológicos na região de Lavras, MG, nos anos 2004 e 2005. Cienc. Agrot., v.33, p.252-260, 2009.

LOPES, F.C.F.; GAMA, M.A.S.; RIBEIRO, C.G.S. et al. Produção de leite com alto teor de CLA - Experiência brasileira. In: PEREIRA, L.G.R.; NOBRE, M.M. et al. (Org.). Pesquisa, desenvolvimento e inovação para sustentabilidade da bovinocultura leiteira. Juiz de Fora, MG: Embrapa Gado de Leite, 2011. p.251-296.
LOPES, M.A.; LAGE, L.A.; LOPES, F.C.F. et al. Economic viability of feeding dairy cows on diets containing different levels of soybean oil. Rev. Bras. Zootec., v.41, p.2085-2091, 2012.

LOPES, M.A.; LIMA, A.L.R.; CARVALHO, F.M. et al. Resultados econômicos de sistemas de produção de leite com diferentes níveis tecnológicos na região de Lavras, MG. Arq. Bras. Med. Vet. Zootec., v.57, p.485-493, 2005.

LOPES, M.A.; SANTOS, G.; AMADO, G.B. Viabilidade econômica da adoção e implantação da rastreabilidade em sistema de produção de bovinos no estado de Minas Gerais. Cienc. Agrot., v.32, p.288-294, 2008.

NATIONAL Research Council - NRC. Nutrient requirements of dairy cattle. 7th. Rev. ed. Washington, D.C.: National Academy of Sciences, 2001. 381p.

PALMQUIST, D.L. Great discoveries of milk for a healthy diet and a healthy life. Rev. Bras. Zootec., v.39, p.465-477, 2010.

SANTOS, G. dos; LOPES, M.A. Indicadores de rentabilidade do centro de custo produção de leite em sistemas intensivos de produção. Bol. Indust. Anim., v.69, p.01-11. 2012.

SOUZA, S.M. Desempenho e perfil de ácidos graxos do leite de vacas alimentadas com óleo de girassol em dietas à base de cana-de-açúcar. 2011. 87f. Tese (Doutorado em Zootecnia) Universidade Federal de Viçosa, Viçosa.

TORAL, P.G.; FRUTOS, P.; BICHI, E. et al. Como aumentar os níveis de CLA no leite dos ruminantes. Albeitar, v.6, p.52-57, 2010. 